\title{
Temperature- and Structural-Dependent Optical Properties and Photophysics of BODIPY Dyes
}

\author{
Sebastian Radunz, ${ }^{a}$ Werner Kraus, ${ }^{a}$ Florian A. Bischoff, ${ }^{b}$ Franziska Emmerling, ${ }^{a, b}$ Harald \\ Rune Tschiche,c and Ute Resch-Genger*a \\ a Department 1 - Analytical Chemistry; Reference Materials, Federal Institute for Materials Research and Testing \\ (BAM), Richard-Willstaetter-Str.11,12489Berlin, Germany.E-mail:ute.resch@bam.de \\ ${ }^{b}$ Department of Chemistry, Humboldt-Universität zu Berlin, Brook-Taylor-Straße 2, 12489Berlin, Germany. \\ c Department of Chemical and ProductSafety, German Federal Institute for RiskAssessment (BfR), Max-Dohrn-Str. \\ 8-10, 10589 Berlin, Germany.
}

\section{Electronic Supplementary Information (ESI)}

\section{Experimental Section}

Synthesis of fluorescent pH sensitive BODIPYs:

The corresponding aldehyde (2.5 mmol, 1.0 eq.) and 2,4-dimethylpyrrole (5.0 mmol, 2.0 eq.) were dissolved in $140 \mathrm{ml}$ dry DCM and $10 \mathrm{ml}$ dry EtOH. After degassing by rapid vacuum-argon cycles (5 times), a few drops of TFA $(30 \mu \mathrm{l})$ were added and the reaction mixture was stirred at room temperature under argon atmosphere in the dark overnight. $p$-Chloranil $(2.5 \mathrm{mmol}, 1.0$ eq.) was added and the mixture was stirred for additional 60 min. Prior addition of $\mathrm{BF}_{3} \cdot \mathrm{OEt}_{2}(25.0 \mathrm{mmol}, 10.0 \mathrm{eq}$.) and $4.3 \mathrm{ml}$ diisopropy lethyla mine (DIPEA) (25.0 mmol, 10.0 eq.), the DCM/EtOH solvent mixture was removed under reduced pressure and replaced by $100 \mathrm{ml}$ of dry $\mathrm{DCM}$ to avoid a reaction between $\mathrm{BF}_{3} \cdot \mathrm{OEt}_{2}$ and $\mathrm{EtOH}$. After portionwise addition, the reaction mixture was stirred for 60 minutes. Subsequently, the reaction mixture was prepurified by carrying out a short silica-gel flash column chromatography with DCM as eluent. The resulting crude mixture was concentrated under reduced pressure and further purified by

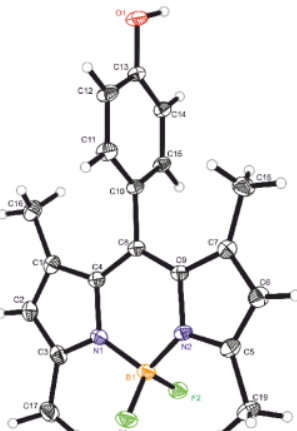

1

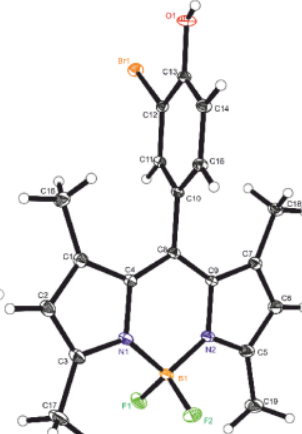

2

'

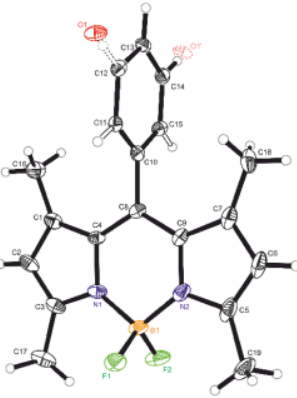

6

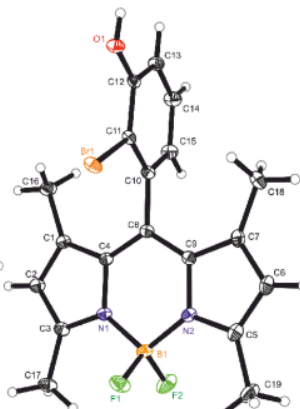

7

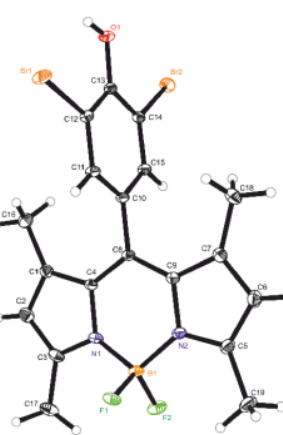

3

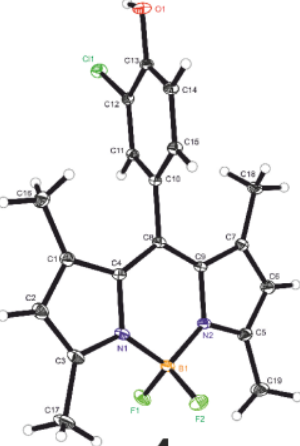

4

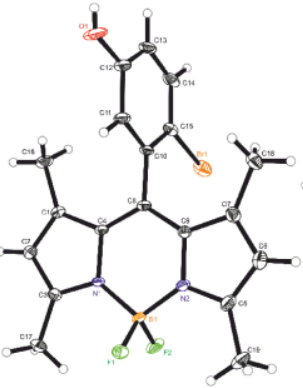

8

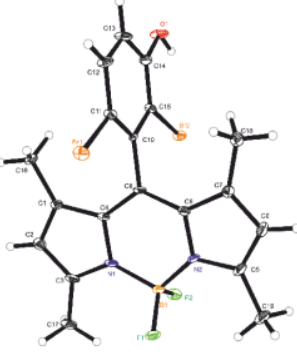

9

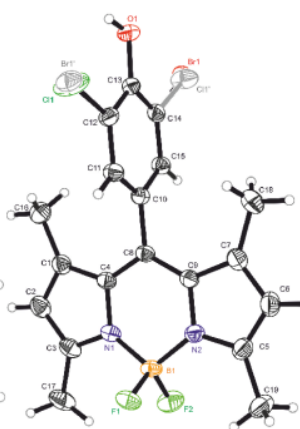

5

Fig. S1 Crystal structures of all synthesized BODIPY dyes. 
Table S1. Selected crystallographic data and structure refinement parameters.

\begin{tabular}{|c|c|c|c|c|c|c|c|c|c|c|}
\hline $\begin{array}{l}\text { Compound } \\
\text { reference }\end{array}$ & 1 & 2 & 3 & 4 & 5 & 6 & 7 & 8 & 9 & 10 \\
\hline \multirow{2}{*}{$\begin{array}{l}\text { Chemical } \\
\text { formula }\end{array}$} & \multicolumn{10}{|c|}{$\mathrm{C}_{19} \mathrm{H}_{19} \mathrm{BF}_{2} \mathrm{~N}_{2} \mathrm{C}_{19} \mathrm{H}_{18} \mathrm{BBrF}_{2} \mathrm{C}_{19} \mathrm{H}_{17} \mathrm{BBr}_{2} \mathrm{FC}_{19} \mathrm{H}_{18} \mathrm{BClF}_{2} \mathrm{C}_{19} \mathrm{H}_{17} \mathrm{BBrClC}_{19} \mathrm{H}_{18} \mathrm{BF}_{2} \mathrm{~N}_{2} \mathrm{C}_{19} \mathrm{H}_{20} \mathrm{BBrF}_{2} \mathrm{C}_{19} \mathrm{H}_{18} \mathrm{BBrF}_{2} \mathrm{C}_{19} \mathrm{H}_{17} \mathrm{BBr}_{2} \mathrm{FC}_{19} \mathrm{H}_{16} \mathrm{BBr}_{3} \mathrm{~F}_{2}$} \\
\hline & 0 & $\mathrm{~N}_{2} \mathrm{O}$ & ${ }_{2} \mathrm{~N}_{2} \mathrm{O}$ & $\mathrm{N}_{2} \mathrm{O}$ & $\mathrm{F}_{2} \mathrm{~N}_{2} \mathrm{O}$ & 0 & $\mathrm{~N}_{2} \mathrm{O}_{2}$ & $\mathrm{~N}_{2} \mathrm{O}$ & ${ }_{2} \mathrm{~N}_{2} \mathrm{O}$ & ${ }_{2} \mathrm{~N}_{2} \mathrm{O}$ \\
\hline $\begin{array}{c}\text { Formula Mass } \\
\qquad / \mathrm{g} \mathrm{mol}^{-1}\end{array}$ & 340.17 & 419.07 & 497.97 & 374.61 & 452.51 & 339.16 & 437.09 & 419.07 & 497.97 & 576.88 \\
\hline $\begin{array}{l}\text { Crystal } \\
\text { system }\end{array}$ & monoclinic & monoclinic & monoclinic & monoclinic & monoclinic & monoclinic & monoclinic & monoclinic & monoclinic & monoclinic \\
\hline$a / \AA$ & 13.8943 & 16.0546 & 12.6348 & 15.8689 & 12.6330 & 13.8906 & 11.4965 & 7.0391 & 13.4725 & 26.5236 \\
\hline$b / \AA$ & 9.6155 & 13.4873 & 10.6680 & 13.4387 & 10.7186 & 25.8723 & 8.9786 & 14.1435 & 19.8851 & 10.3333 \\
\hline$c / \AA$ & 13.8974 & 16.4137 & 15.1098 & 16.2719 & 15.1341 & 14.1900 & 18.2352 & 20.8508 & 7.4708 & 17.5893 \\
\hline$\alpha /^{\circ}$ & 90 & 90 & 90 & 90 & 90 & 90 & 90 & 90 & 90 & 90 \\
\hline$\beta /^{\circ}$ & 113.810 & 96.9234 & 107.3285 & 95.8495 & 107.1048 & 91.0486 & 91.431 & 91.1289 & 109.6622 & 125.3134 \\
\hline$\gamma /^{\circ}$ & 90 & 90 & 90 & 90 & 90 & 90 & 90 & 90 & 90 & 90 \\
\hline $\begin{array}{c}\text { Unit cell } \\
\text { volume } / \AA^{3}\end{array}$ & 1698.7 & 3528.2 & 1944.18 & 3452.0 & 1958.64 & 5098.8 & 1881.68 & 2075.45 & 1884.74 & 3933.8 \\
\hline $\begin{array}{c}\text { Temperature } \\
/ \mathrm{K}\end{array}$ & $150(2)$ & $150(2)$ & $150(2)$ & $150(2)$ & $297(2)$ & $150(2)$ & $150(2)$ & $150(2)$ & $150(2)$ & $150(2)$ \\
\hline Space group & $P 21 / n$ & $P 21 / n$ & $P 21 / n$ & $P 21 / n$ & $P 21 / n$ & $P 21 / c$ & $C c$ & $P 21 / n$ & $C c$ & $C 2 / c$ \\
\hline $\begin{array}{l}\text { No. of formula } \\
\text { units per unit } \\
\quad \text { cell, } Z\end{array}$ & 4 & 8 & 4 & 8 & 4 & 12 & 4 & 4 & 4 & 8 \\
\hline $\begin{array}{c}\text { Absorption } \\
\text { coefficient, } \\
\mu / \mathrm{mm}^{-1}\end{array}$ & 0.097 & 2.361 & 4.199 & 0.252 & 2.264 & 0.097 & 2.220 & 2.007 & 4.332 & 6.184 \\
\hline $\begin{array}{l}\text { No. of } \\
\text { reflections } \\
\text { measured }\end{array}$ & 29038 & 107330 & 74846 & 92931 & 42661 & 130154 & 27890 & 67769 & 30356 & 101847 \\
\hline $\begin{array}{c}\text { No. of } \\
\text { independent } \\
\text { reflections }\end{array}$ & 4224 & 10821 & 9966 & 11048 & 4887 & 12704 & 4698 & 6364 & 6201 & 13128 \\
\hline Rint & 0.1955 & 0.0933 & 0.1082 & 0.1039 & 0.1257 & 0.1993 & 0.0936 & 0.1050 & 0.1371 & 0.0817 \\
\hline $\begin{array}{c}\text { Final } R_{1} \\
\text { values }(I> \\
2 \sigma(I))\end{array}$ & 0.0736 & 0.0407 & 0.0459 & 0.0628 & 0.0440 & 0.1276 & 0.0335 & 0.0569 & 0.0546 & 0.0628 \\
\hline $\begin{array}{c}\text { Final } w R\left(F^{2}\right) \\
\text { values }(I> \\
2 \sigma(I))\end{array}$ & 0.1696 & 0.0986 & 0.1120 & 0.1494 & 0.1111 & 0.2203 & 0.0852 & 0.1203 & 0.1181 & 0.1156 \\
\hline $\begin{array}{c}\text { Final } R_{1} \\
\text { values (all } \\
\text { data) }\end{array}$ & 0.1274 & 0.0520 & 0.0739 & 0.0878 & 0.0654 & 0.1943 & 0.0342 & 0.0719 & 0.0775 & 0.1054 \\
\hline $\begin{array}{c}\text { Final } w R\left(F^{2}\right) \\
\text { values (all } \\
\text { data) }\end{array}$ & 0.1989 & 0.1060 & 0.1252 & 0.1640 & 0.1268 & 0.2431 & 0.0859 & 0.1272 & 0.1455 & 0.1287 \\
\hline $\begin{array}{l}\text { Goodness of } \\
\text { fit on } F^{2}\end{array}$ & 1.034 & 1.022 & 1.013 & 1.051 & 1.074 & 1.222 & 1.044 & 1.085 & 1.071 & 1.084 \\
\hline CCDC number & 1969036 & 1969037 & 1969038 & 1969039 & 1969040 & 1969041 & 1969042 & 1969043 & 1969044 & 1969045 \\
\hline
\end{tabular}




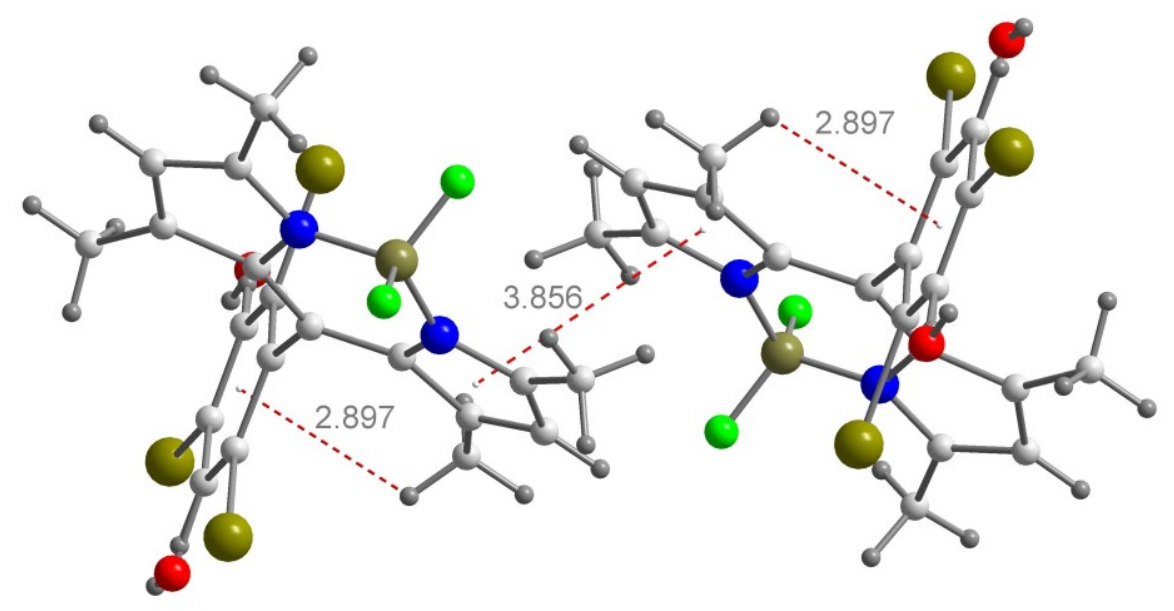

Fig. S2 Crystal packing and stabilizing inter- and intramolecular interactions.

a)

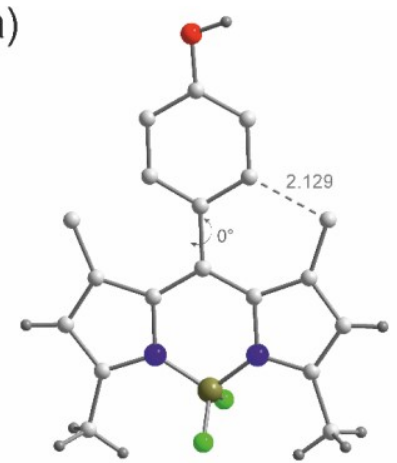

Fig. S3 Hypothetical rotation of the meso-aryl along the C8-C10 axis of BODIPY 1 and 7.

b)

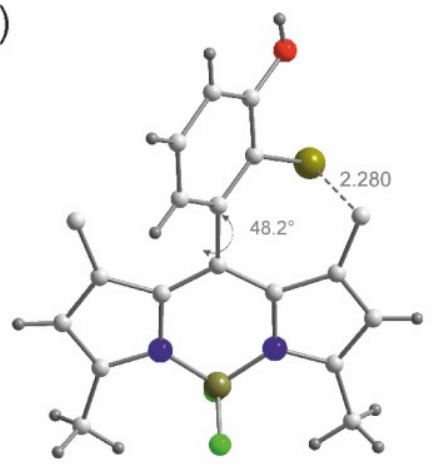


a)

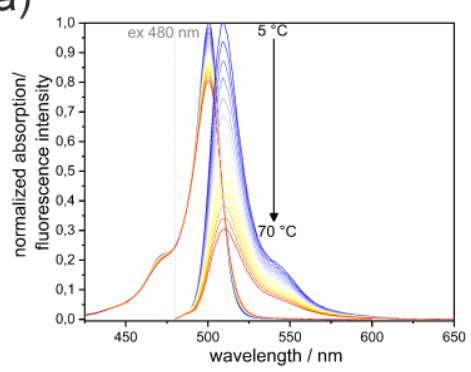

b)

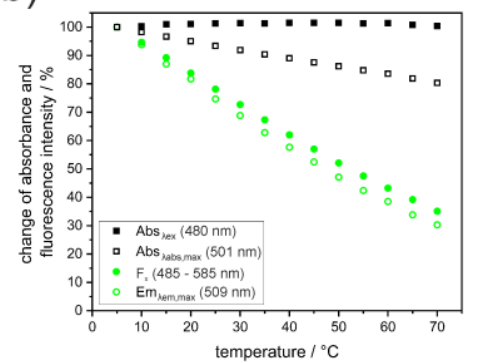

c)

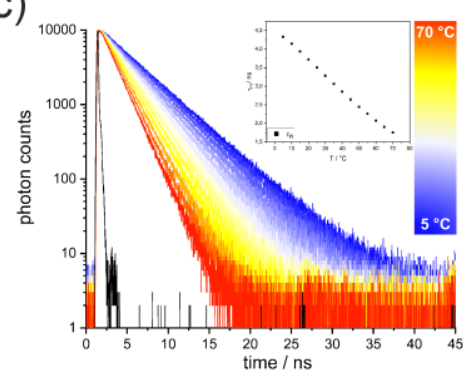

Fig. S4 a) Temperature-dependent normalized absorption and normalized fluorescence intensity of non-sterically hindered compound 2 upon excitation at $480 \mathrm{~nm}$. b) Percentage changes of the absorbance (black squares) at excitation wavelength and at maximum absorbance (full and open symbols, respectively), and percentage changes of the fluorescence intensity (green circles) for integrated emission intensity and at emission maximum (full and open symbols, respectively) in dependence of temperature for compound 2. c) Fluorescence decay curves for compound 2 in dependence of the temperature (black line represents the instrument response function (IRF)). The inset shows the mono exponential fitted fluor escence lifetime as function of temperature.

a)

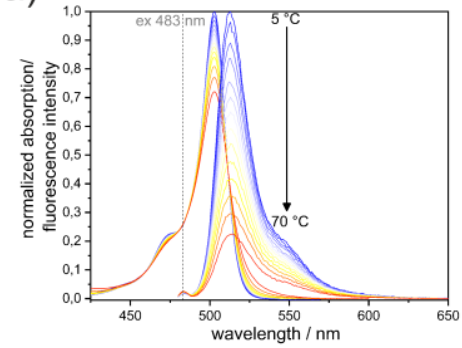

b)

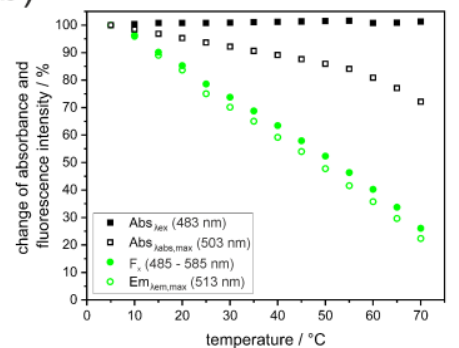

C)

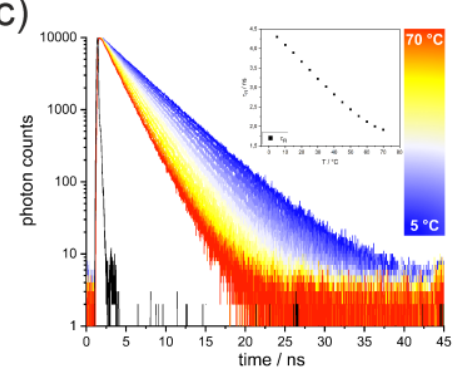

Fig. S5 a) Temperature-dependent normalized absorption and normalized fluorescence intensity of non-sterically hindered compound $\mathbf{3}$ upon excitation at $483 \mathrm{~nm}$. b) Percentage changes of the absorbance (black squares) at excitation wavelength and at maximum absorbance (full and open symbols, respectively), and percentage changes of the fluorescence intensity (green circles) for integrated emission intensity and at emission maximum (full and open symbols, respectively) in dependence of temperature for compound 3. c) Fluorescence decay curves for compound 3 in dependence of the temperature (black line represents the instrument response function (IRF)). The inset shows the mono exponential fitted fluor escence lifetime as function of temperature.

a)

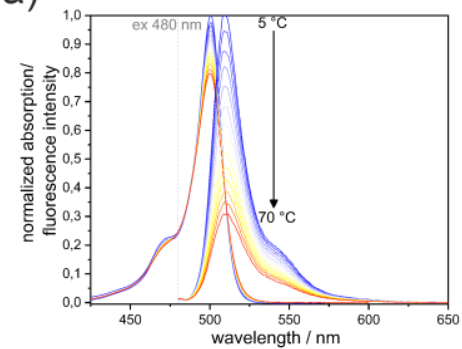

b)

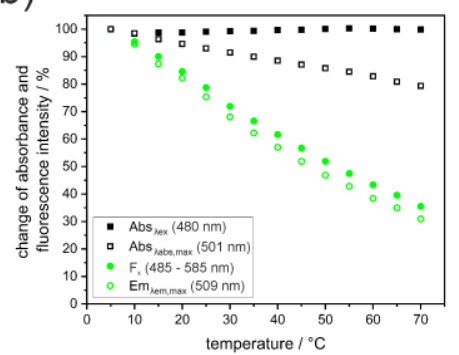

c)

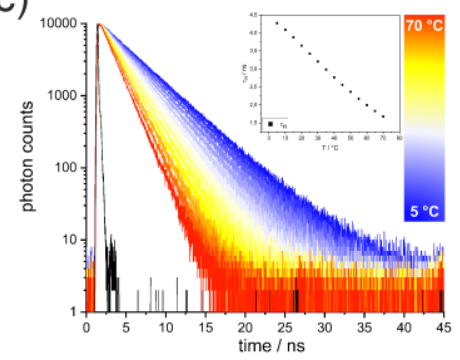

Fig. S6 a) Temperature-dependent normalized absorption and normalized fluorescence intensity of non-sterically hindered compound $\mathbf{4}$ upon excitation at $480 \mathrm{~nm}$. b) Percentage changes of the absorbance (black squares) at excitation wavelength and at maximum absorbance (full and open symbols, respectively), and percentage changes of the fluorescence intensity (green circles) for integrated emission intensity and at emission maximum (full and open symbols, respectively) in dependence of temperature for compound 4. c) Fluorescence decay curves for compound $\mathbf{4}$ in dependence of the temperature (black line represents the instrument response function (IRF)). The inset shows the mono exponential fitted fluorescence lifetime as function of temperature.

a)

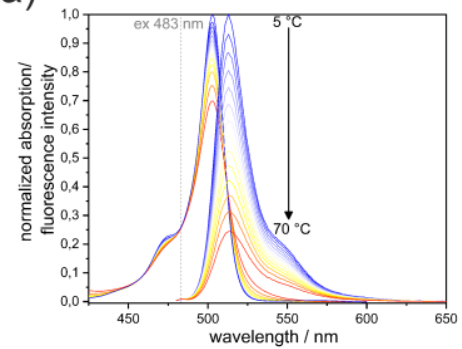

b)

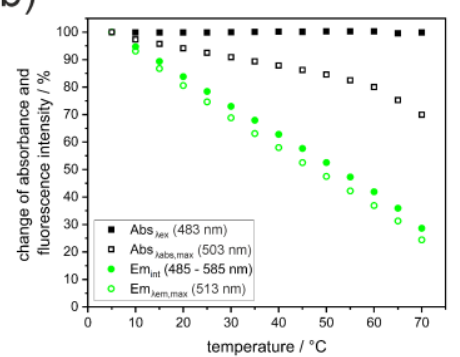

c)

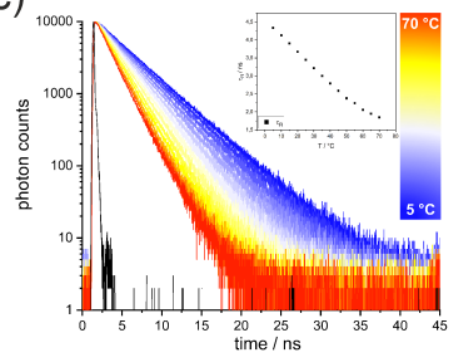

Fig. S7 a) Temperature-dependent normalized absorption and normalized fluorescence intensity of non-sterically hindered compound $\mathbf{5}$ upon excitation at $483 \mathrm{~nm}$. b) Percentage changes of the absorbance (black squares) at excitation wavelength and at maximum absorbance (full and open symbols, respectively), and percentage changes of the fluorescence intensity (green circles) for integrated emission inten sity and at emission maximum (full and open symbols, respectively) in dependence of temperature for compound 5. c) Fluorescence decay curves for compound $\mathbf{5}$ in dependence of the temperature (black line represents the instrument response function (IRF)). The inset shows the mono exponential fitted fluorescence lifetime as function of temperature. 
a)

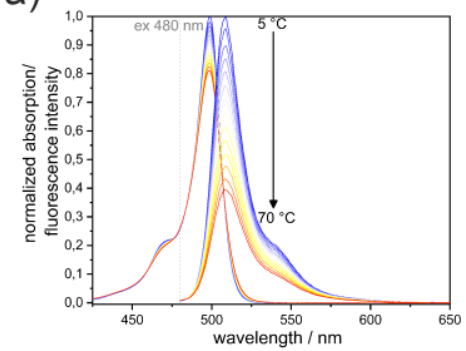

b)

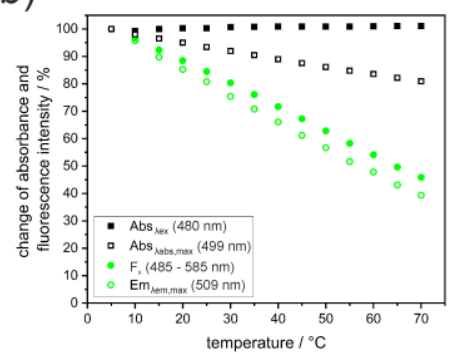

c)

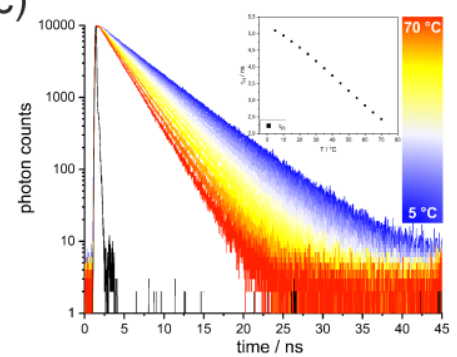

Fig. S8 a) Temperature-dependent normalized absorption and normalized fluorescence intensity of non-sterically hindered compound $\mathbf{6}$ upon excitation at $480 \mathrm{~nm}$. b) Percentage changes of the absorbance (black squares) at excitation wavelength and at maximum absorbance (full and open symbols, respectively), and percentage changes of the fluorescence intensity (green circles) for integrated emission intensity and at emission maximum (full and open symbols, respectively) in dependence of temperature for compound 6. c) Fluorescence decay curves for compound 6 in dependence of the temperature (black line represents the instrument response function (IRF)). The inset shows the mono exponential fitted fluor escence lifetime as function

a)

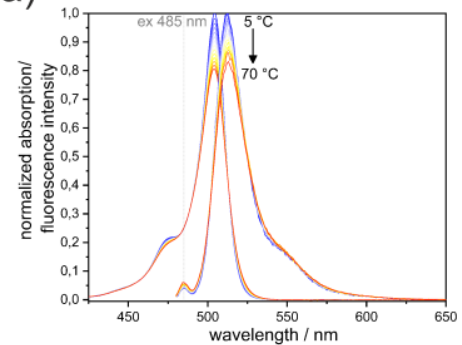

b)

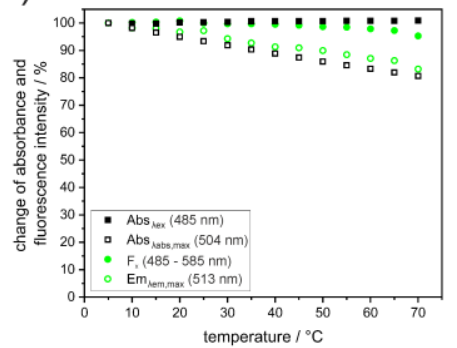

c)

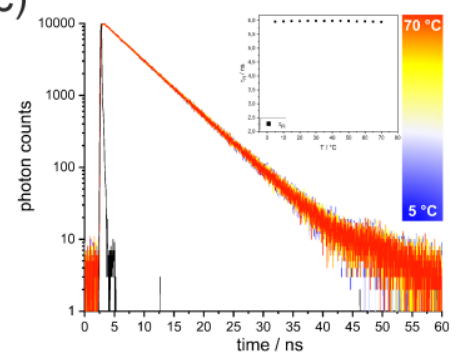

of temperature.

Fig. S9a) Temperature-dependent normalized absorption and normalized fluorescence intensity of sterically hindered compound 8 upon excitation at $485 \mathrm{~nm}$. b) Percentage changes of the absorbance (black squares) at excitation wavelength and at maximum absorbance (full and open symbols, respectively), and percentage changes of the fluorescence intensity (green circles) for integrated emission intensity and at emi ssion maximum (full and open symbols, respectively) in dependence of temperature for compound 8. c) Fluorescence decay curves for compound 8 in dependence of the temperature (black line represents the instrument response function (IRF)). The inset shows the mono exponential fitted fluor escence lifetime as function of temperature.

a)

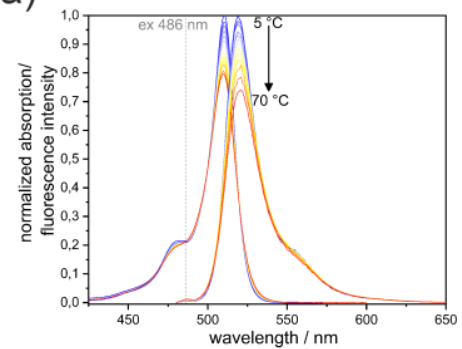

b)

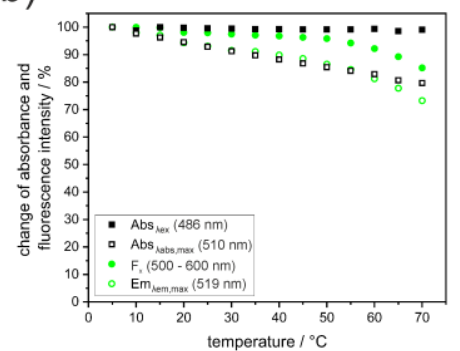

c)

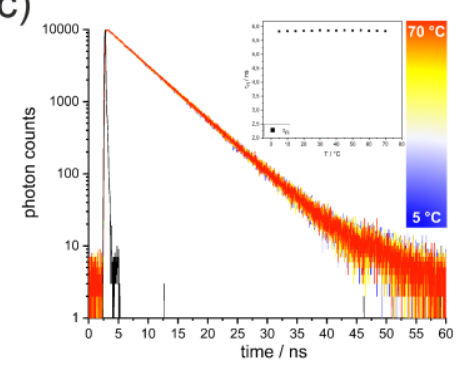

Fig. S10 a) Temperature-dependent normalized absorption and normalized fluorescence intensity of sterically hindered compound $\mathbf{9}$ upon excitation at $486 \mathrm{~nm}$. b) Percentage changes of the absorbance (black squares) at excitation wavelength and at maximum absorbance (full and open symbols, respectively), and percentage changes of the fluorescence intensity (green circles) for integrated emission intensity and at emission maximum (full and open symbols, respectively) in dependence of temperature for compound 9. c) Fluorescence decay curves for compound 9 in dependence of the temperature (black line represents the instrument response function (IRF)). The inset shows the mono exponential fitted fluor escence lifetime as function of temperature.

a)

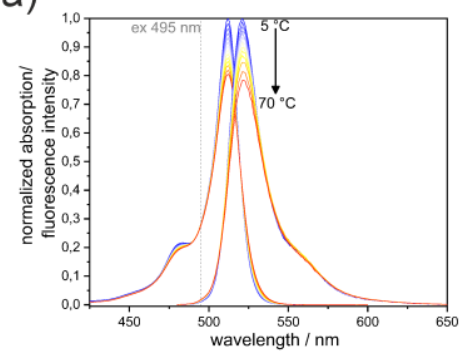

b)

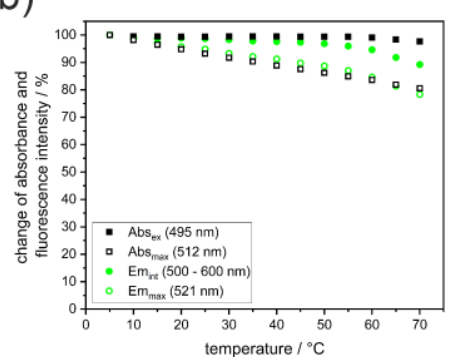

c)

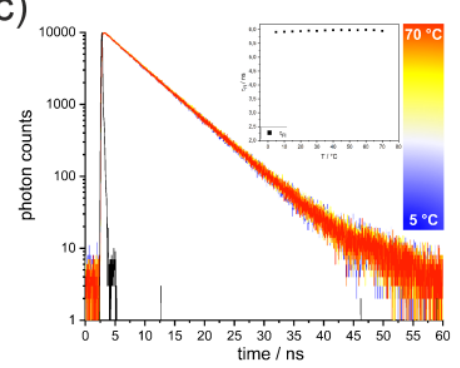

Fig. S11 a) Temperature-dependent normalized absorption and normalized fluorescence intensity of sterically hindered compound $\mathbf{1 0}$ upon excitation at $495 \mathrm{~nm}$. b) Percentage changes of the absorbance (black squares) at excitation wavelength and at maximum absorbance (full and open symbols, respectively), and percentage changes of the fluorescence intensity (green circles) for integrated emission intensity and at emission maximum (full and open symbols, respectively) in dependence of temperature for compound 10. c) Fluorescence decay curves for compound $\mathbf{1 0}$ in dependence of the temperature (black line represents the instrument response function (IRF)). The inset shows the mono exponential fitted fluorescence lifetime as function of temperature. 
Table S2. Calculated absolute and relative energies of the minimum (min1, min2), the transition (TS1, TS2) and intermediate (IS) states and corresponding dihedral angles of BODIPY compounds $1,3,6,7,8$ and 9.

\begin{tabular}{|c|c|c|c|c|c|c|c|c|c|c|c|}
\hline \multirow{2}{*}{ Dye } & \multicolumn{5}{|c|}{$\begin{array}{l}\text { absolute energy } / E_{h} \\
\text { (relative energy } / \text { kcalmol }^{-1} \text { ) }\end{array}$} & \multicolumn{5}{|c|}{ dihedral angle ${ }^{\circ}{ }^{\circ}$} & \multirow{2}{*}{$\begin{array}{c}t_{1 / 2^{b}} / s\left(20^{\circ} \mathrm{C}\right) \\
m i n->T S 1\end{array}$} \\
\hline & $\begin{array}{c}\min \\
1\end{array}$ & TS 1 & IS & TS 2 & $\min 2$ & $\min 1$ & TS 1 & IS & TS 2 & $\min 2$ & \\
\hline 1 & 0 & 16.4 & 16.1 & 16.4 & 0 & 90 & 14 & 3 & -14 & -90 & 0.2 \\
\hline 3 & 0 & 16.7 & - & - & 0.03 & 90 & 14 & & & -93 & 0.3 \\
\hline 6 & 0 & 12.9 & 12.7 & 12.8 & 0 & 40 & 13 & 3 & -13 & -40 & $4.8 * 10^{-4}$ \\
\hline 7 & 0 & 42.3 & - & - & 0 & & 34 & & & & $3.9 * 10^{18}$ \\
\hline 8 & 0 & 38.2 & - & - & 0.3 & 89 & 29 & & & -92 & $3.1 * 10^{15}$ \\
\hline 9 & 0 & 49.2 & 46.6 & 49.2 & 0 & 90 & 39 & 10.5 & -39 & -90 & $5.1 * 10^{23}$ \\
\hline
\end{tabular}

b Half-life calculated assuming first order reaction kinetics $t_{1 / 2}=\frac{\ln (2)}{k}$, with $k=\kappa \frac{k_{B} T}{h} e^{-\frac{\Delta G}{R T}}$ from Eyring equation with $\mathrm{k}_{\mathrm{B}}=\mathrm{Boltzmann}$ constant, $\mathrm{T}=$ 293.15 K, h = Planck constant, $\kappa=1$ (transmission coefficient) and $\mathrm{R}=$ gas constant.

Table S3. Temperature-dependent non-radiative decay rates $\mathrm{k}_{\mathrm{nr}}$.

\begin{tabular}{cccc}
\hline \multirow{2}{*}{ Dye } & \multicolumn{3}{c}{$k_{n r}(\mathrm{~T}) / 10^{8} \mathrm{~s}^{-1}$} \\
\cline { 2 - 4 } & $5{ }^{\circ} \mathrm{C}$ & $20^{\circ} \mathrm{C}$ & $70{ }^{\circ} \mathrm{C}$ \\
\hline $\mathbf{1}$ & $0.66 \pm 0.05$ & $1.16 \pm 0.05$ & $4.91 \pm 0.05$ \\
$\mathbf{2}$ & $0.62 \pm 0.06$ & $1.07 \pm 0.06$ & $4.29 \pm 0.06$ \\
$\mathbf{3}$ & $0.72 \pm 0.05$ & $1.15 \pm 0.05$ & $4.32 \pm 0.05$ \\
$\mathbf{4}$ & $0.71 \pm 0.07$ & $1.12 \pm 0.07$ & $4.53 \pm 0.07$ \\
$\mathbf{5}$ & $0.71 \pm 0.05$ & $1.15 \pm 0.05$ & $4.36 \pm 0.05$ \\
$\mathbf{6}$ & $0.29 \pm 0.02$ & $0.55 \pm 0.02$ & $2.57 \pm 0.02$ \\
$\mathbf{7}$ & $0.15 \pm 0.01$ & $0.15 \pm 0.01$ & $0.24 \pm 0.01$ \\
$\mathbf{8}$ & $0.18 \pm 0.01$ & $0.18 \pm 0.01$ & $0.30 \pm 0.01$ \\
$\mathbf{9}$ & $0.18 \pm 0.01$ & $0.21 \pm 0.01$ & $0.43 \pm 0.01$ \\
$\mathbf{1 0}$ & $0.20 \pm 0.01$ & $0.22 \pm 0.01$ & $0.37 \pm 0.01$ \\
\hline
\end{tabular}

Table S4..Fitting parameters fot the determination of $\Delta E_{A}$ for non-radiative decay of the first exited state $\mathrm{S}_{1}$

\begin{tabular}{|c|c|c|c|c|c|c|c|c|c|}
\hline Dye & $\begin{array}{c}\frac{\Delta \mathrm{E}_{\mathrm{A}}}{\mathrm{R}}\left(\Phi_{\mathrm{Fl}}\right) / \\
\mathrm{K}^{\mathrm{a}}\end{array}$ & $\begin{array}{c}\mathrm{E}_{\mathrm{A}}\left(\Phi_{\mathrm{Fl}}\right) / \\
\text { kcalmol-1a }^{-1 a}\end{array}$ & $\ln (\mathrm{c} 2)\left(\Phi_{\mathrm{Fl}}\right)^{\mathrm{a}}$ & $\mathrm{R}^{2}\left(\Phi_{\mathrm{Fl}}\right)$ & $\begin{array}{c}\frac{\Delta \mathrm{E}_{\mathrm{A}}}{\mathrm{R}}\left(\tau_{\mathrm{Fl}}\right) / \\
\mathrm{K}^{\mathrm{b}}\end{array}$ & $\begin{array}{c}\mathrm{E}_{\mathrm{A}}\left(\tau_{\mathrm{Fl}}\right) / \\
\mathrm{kcalmol}^{-1 \mathrm{~b}}\end{array}$ & $\ln (\mathrm{A})\left(\tau_{\mathrm{Fl}}\right)$ & $\begin{array}{l}\mathrm{c}_{3}\left(\tau_{\mathrm{Fl}}\right) / \\
10^{8} \mathrm{~s}^{-1 *}\end{array}$ & $\mathrm{R}^{2}\left(\tau_{\mathrm{Fl}}\right)$ \\
\hline 1 & $-3030 \pm 19$ & $6.02 \pm 0.30$ & $9,97 \pm 0,06$ & 0,999 & $-2981 \pm 13$ & $5.92 \pm 0.30$ & $7,94 \pm 0,04$ & 1,75 & 0,999 \\
\hline 2 & $-3058 \pm 12$ & $6.08 \pm 0.30$ & $10,00 \pm 0,04$ & 0,999 & $-2956 \pm 11$ & $5.87 \pm 0.29$ & $7,68 \pm 0,03$ & 1,78 & 0,999 \\
\hline 3 & $-3255 \pm 133$ & $6.47 \pm 0.32$ & $10,79 \pm 0,43$ & 0,979 & $-3029 \pm 10$ & $6.02 \pm 0.22$ & $7,94 \pm 0,03$ & 1,78 & 0,999 \\
\hline 4 & $-2972 \pm 30$ & $5.91 \pm 0.30$ & $9,80 \pm 0,10$ & 0,999 & $-2989 \pm 19$ & $5.94 \pm 0.30$ & $7,84 \pm 0,06$ & 1,79 & 0,999 \\
\hline 5 & $-3101 \pm 100$ & $6.16 \pm 0.31$ & $10,26 \pm 0,32$ & 0,987 & $-3046 \pm 7$ & $6.05 \pm 0.23$ & $8,02 \pm 0,02$ & 1,78 & 0,998 \\
\hline 6 & $-3289 \pm 32$ & $6.54 \pm 0.33$ & $10,11 \pm 0,11$ & 0,999 & $-3241 \pm 28$ & $6.44 \pm 0.32$ & $8,02 \pm 0,09$ & 1,70 & 0,999 \\
\hline 7 & $-739 \pm 56$ & $1.47 \pm 0.29$ & $0,21 \pm 0,18$ & 0,927 & $-\mathrm{c}$ & & $-c$ & $-c$ & $-c$ \\
\hline 8 & $-751 \pm 67$ & $1.49 \pm 0.30$ & $0,52 \pm 0,21$ & 0,913 & $-c$ & & $-c$ & $-c$ & $-c$ \\
\hline 9 & $-1380 \pm 109$ & $2.74 \pm 0.55$ & $2,68 \pm 0,44$ & 0,895 & $-c$ & & $-c$ & $-c$ & $-c$ \\
\hline 10 & $-927 \pm 71$ & $1.84 \pm 0.37$ & $1,27 \pm 0,27$ & 0,909 & $-c$ & & $-c$ & $-c$ & $-c$ \\
\hline
\end{tabular}

aiteratively determined following eq. 6 with $\mathrm{c}_{1}=0$

b iteratively determined following eq. 8

${ }^{c}$ could not be determined

\section{S. Radunz, H. R. Tschiche, D. Moldenhauer, U. Resch-Genger, Sensors and Actuators B: Chemical 2017, 251, 490-494.}

